\title{
Identifikasi lanskap Karang Bengang di Desa Buahan, Kecamatan Tabanan, Kabupaten Tabanan
}

\author{
I Gede Komang Adi Wijaya ${ }^{1}$, Ni Wayan Febriana Utami ${ }^{\star \star}$, I Gusti Alit Gunadi² \\ 1. Program Studi Arsitektur Pertamanan, Fakultas Pertanian, Universitas Udayana, Jl. P.B. Sudirman, \\ Denpasar, Indonesia \\ 2. Program Studi Agroekoteknologi, Fakultas Pertanian, Universitas Udayana, Jl. P.B. Sudirman, Denpasar, \\ Indonesia \\ *E-mail : wayan_febriana@unud.ac.id
}

\begin{abstract}
Landscape identification of karang bengang at Buahan Village, Tabanan Subdistrict, Tabanan Regency. This research is motivated by the absence of the spatial pattern of landscape character of karang bengang at Buahan Village. Karang bengang is an open space that is located between the villages as a nonresidential area. The existence of karang bengang increasingly rare in Bali, due to land use change. This study aims to identify and map the spatial patterns and characters of karang bengang at Buahan Village, Tabanan sub-district, Tabanan Regency. The method used in this research was survey method and data were collected by conducting observation, interviews, and literature study. For data analysis, it used qualitative data analysis methods and the results was presented in the form of illustration of spatial pattern of Tabanan Subdistrict, illustration of the spatial pattern of Desa Buahan, and map of the karang bengang area at Buahan Village. Based on the analysis, it was found that the landscape character of karang bengang at Buahan Village was influenced by biophysical (climate, accessibility, softscape, and hardscape, spatial patterns, land cover) and social aspects (demographic, socio-cultural, and economic), as well as traditional Balinese space patterns of Tri Hita Karana (the concept of reciprocity of humans with nature implements natural use areas such as pancoran, rice fields, fields, humans and humans implementing human interaction areas such as farmer huts, humans and God implement sacred areas such as Pelinggih Catu to achieve harmony) and Tri Mandala (the concept of division of three levels of space). Furthermore, the role of the community element is needed in strengthening the village-owned regulation and village construction in order to preserve the karang bengang at Buahan Village.
\end{abstract}

Keywords: Buahan village, spatial patterns, landscape character, karang bengang.

\section{Pendahuluan}

Bali merupakan salah satu provinsi di Indonesia yang memiliki konsep tata ruang tradisional baik konsep ruang tradisional di dalam pekarangan maupun di luar pekarangan rumah. Konsep ruang tradisional Bali salah satunya adalah karang bengang. Karang bengang yang bisa dikatakan sebagai ruang terbuka berupa lahan pertanian yang dikelola subak bagian dari zona penyangga (Peraturan Presiden Republik Indonesia Nomor 51 Tahun 2014). Menurut Windia dalam Karma (2018) karang bengang berupa tanah kosong yang panjang dan luas, yang berupa tanah persawahan, perkebunan maupun hutan. Berdasarkan beberapa pendapat dan kondisi di lapangan, maka karang bengang di Desa Buahan dapat dimaknai ruang terbuka sebagai kawasan non permukiman yang terletak antar desa yang berada diantara jalan dan diapit oleh dua sungai yang memiliki fungsi sebagai lahan persawahan, tegalan, hutan, serta wadah dalam kegiatan keagaman dalam upaya konservasi lahan berbasis pelestarian budaya yang diwariskan turuntemurun.

Kabupaten Tabanan dikenal sebagai lumbung padi di provinsi Bali karena memiliki area persawahan yang cukup luas dan terbagi menjadi beberapa subak, yang juga berfungsi sebagai ruang terbuka. Ruang terbuka yang dimiliki Kabupaten Tabanan merupakan lahan tak terbangun berupa area persawahan, tegalan maupun hutan sebagai implementasi dari konsep karang bengang. Seiring perkembangan penggunaan lahan, yang mengarah kepada alih fungsi lahan, Desa Buahan merupakan salah satu desa yang mempertahankan ruang terbukanya dari desakan alih fungsi lahan menjadi lahan terbangun, salah satu ruang terbuka yang tetap dipertahankan adalah karang bengang. Desa Buahan adalah desa yang terletak di 
Kecamatan Tabanan, Kabupaten Tabanan, Provinsi Bali. Desa Buahan batas sebelah Utara adalah Desa Tunjuk, dan sebelah selatan Desa Buahan berbatasan dengan Desa Denbantas. Desa Buahan memiliki luas wilayah 6,4586 km² (BPS Kabupaten Tabanan, 2018). Identifikasi terhadap lanskap karang bengang sebagai konsep tata ruang yang muncul dari adanya kearifan lokal masyarakat yang masih ada sampai saat ini, perlu untuk diidentifikasi. Patut diduga karang bengang di Desa Buahan, Kecamatan Tabanan, Kabupaten Tabanan memiliki pola ruang dan karakter pembentuk lanskap tertentu sehingga penelitian mengenai identifikasi karang bengang ini perlu dilakukan.

\section{Metode Penelitian}

\subsection{Lokasi dan Waktu Penelitian}

Penelitian ini dilakukan pada area karang bengang di Desa Buahan, Kecamatan Tabanan, Kabupaten Tabanan, Provinsi Bali (Gambar 1). Penelitian dilaksanakan selama 12 bulan mulai bulan Februari 2019 sampai bulan Februari 2020.

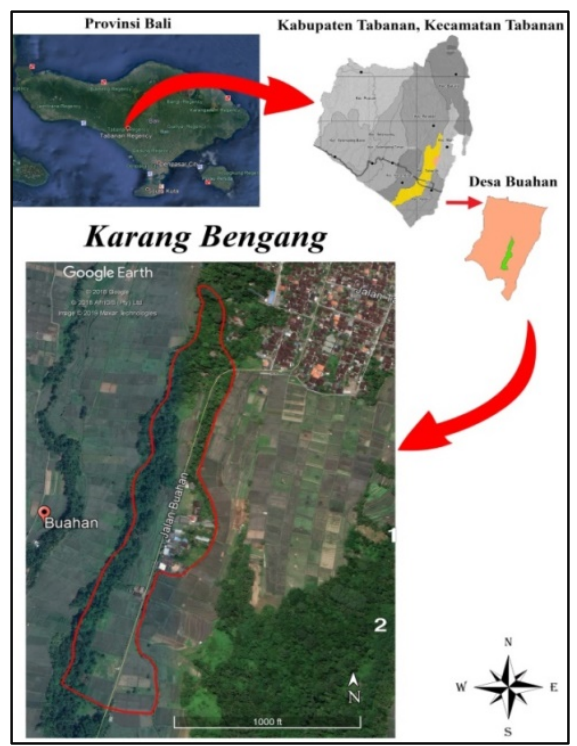

Gambar 1. Lokasi Penelitian

(Sumber: Google Earth, 2019)

\subsection{Alat dan Bahan}

Penelitian ini menggunakan alat dan bahan antara lain perangkat keras (hardware) seperti komputer (laptop), alat tulis, kamera dan GPS serta perangkat lunak (software) seperti AutoCAD, ArcMap 10.4.1, Adobe Photoshop, dan Ms. Word, dan peta administrasi Kabupaten Tabanan.

\subsection{Jenis dan Sumber Data}

Data yang dikumpulkan dalam penelitian ini berupa data primer dan data sekunder. Data primer berupa pengumpulan data yang diperoleh melalui pengamatan langsung di lapangan dengan melakukan observasi dan wawancara. Sedangkan data sekunder merupakan data yang diperoleh dari pustaka dan sumber-sumber tertulis. Data sekunder mencakup studi pustaka dari buku-buku, jurnal ilmiah, media internet dan peraturan perundang-undangan (Sugiyono, 2010). Adapun 3 komponen dalam observasi seperti pada Tabel 1.

Tabel 1. Tiga Komponen Observasi

\begin{tabular}{ccccc}
\hline & Biofisik & Sosial & Ekonomi & Budaya \\
\hline Tempat & $\sqrt{ }$ & - & - & - \\
Aktor & - & $\sqrt{ }$ & $\sqrt{ }$ & $\sqrt{ }$ \\
Aktivitas & - & $\sqrt{ }$ & & $\sqrt{ }$ \\
\hline
\end{tabular}

Sumber : Sugiyono, 2010 


\subsection{Analisis Data}

Data hasil penelitian yang telah dikumpulkan kemudian ditabulasi, dipetakan, dan diinterpretasikan kemudian dianalisis secara kualitatif dengan menyimpulkan berdasarkan teori McClelland. Analisis kualitatif yaitu metode yang digunakan dalam analisis data pada objek alamiah, dimana peneliti sebagai instrumen kunci, pengambilan data dilakukan sesuai dengan tujuan penelitian (Sugiyono, 2004). Setelah dilakukan analisis data hasil observasi, wawancara dan studi pustaka, selanjutnya dilakukan tahap sintesis yaitu hasil dari penelitian, berupa pemetaan pola ruang dan karakter pembentuk lanskap karang bengang di Desa Buahan, Kecamatan Tabanan, Kabupaten Tabanan yang dilihat dari analisis aspek biofisik maupun aspek sosial.

\subsection{Batasan Penelitian}

Penelitian dibatasi pada studi identifikasi karang bengang di Desa Buahan, Kecamatan Tabanan, Kabupaten Tabanan dan sebatas area karang bengang dengan luas $70.176 \mathrm{~m}^{2}$.

\section{Hasil dan Pembahasan}

\subsection{Gambaran Umum Karang bengang Desa Buahan}

Karang bengang di Desa Buahan terletak pada Kecamatan Tabanan, Kabupaten Tabanan, Provinsi Bali yang terletak antara $8^{\circ} 29^{\prime} 3,49^{\prime}-8^{\circ} 30^{\prime} 38,42^{\prime}$ Lintang Selatan dan $115^{\circ} 8^{\prime} 23,35^{\prime}$ - $115^{\circ} 9^{\prime} 6,97$ Bujur Timur. Desa Buahan terletak pada ketinggian 165-227 mdpl. Total luas wilayah Desa Buahan adalah 6,4586 km² (Monografi Desa Buahan, 2019).

Karang bengang di Desa Buahan sebagai kawasan yang berada di Desa Buahan, Kecamatan Tabanan, Kabupaten Tabanan, Provinsi Bali. Adapun batas-batas administrasi dari Desa Buahan yaitu di Utara Desa Tunjuk, Selatan dan Barat Desa Denbatas, dan batas Timur Tukad Yeh Panahan. Karang bengang di Desa Buahan memiliki aksesibilitas dengan jaringan jalan primer yang berperan sebagai akses utama, akses jalan ini menggunakan perkerasan aspal. Aksesibilitas menuju karang bengang di Desa Buahan tergolong mudah dijangkau karena meliputi jalan kabupaten. Jalan kabupaten berupa jalan primer yang menghubungkan antar desa. Karang bengang di Desa Buahan didominasi lahan persawahan dan tegalan maupun hutan yang menjadi batas sebelah selatan karang bengang adalah Pura Dalem Desa Adat Buahan, disebelah Barat dibatasi oleh sungai yeh tabah, dan di Utara sampai di Timur dibatasi sungai yeh pembungan, Desa Buahan, Kecamatan Tabanan, Kabupaten Tabanan.

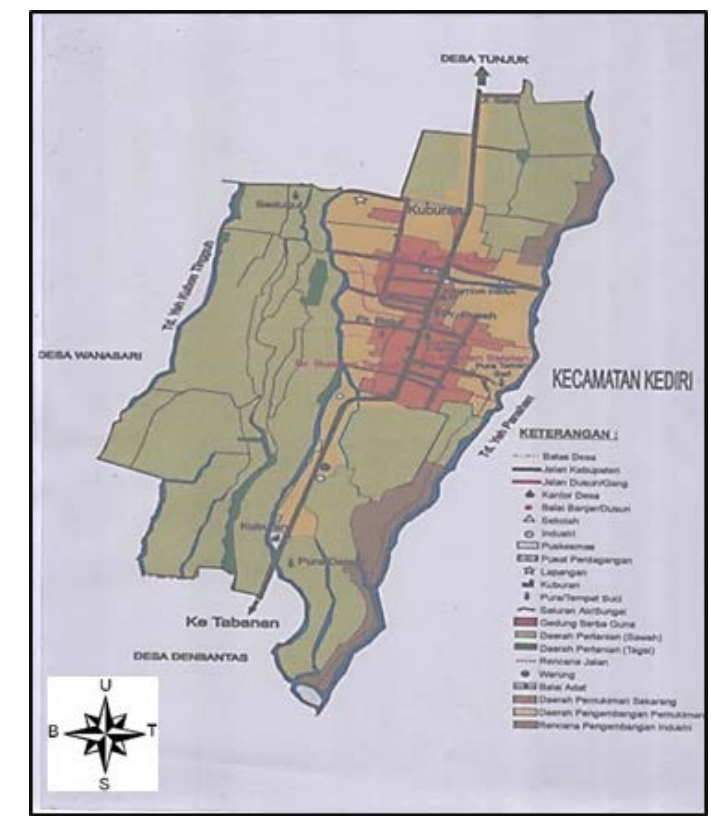

Gambar 2. Dokumentasi Wilayah Administratif Desa Buahan

(Sumber: Monografi Desa Buahan, 2019) 


\subsubsection{Sejarah Desa Buahan}

Berdasarkan hasil wawancara kasi pemerintahan Desa Buahan Bapak I Komang Mariana dijelaskan dari sesepuh Desa Buahan, sejarah desa berkaitan dengan sejarah Arya Kenceng yang terdapat dalam Babad Arya Tabanan tahun saka 1859. Didalam Babad Arya Tabanan diceritakan bahwa Puri beliau terletak disebelah selatan Pura Bale Agung Desa Buahan (kiduling Bale Agun) dan tamannya terletak disebelah Tenggara Desa Buahan. Kemudian beliau wafat dan dibuatkan penghormatan atas jasa beliau dengan dibuatkannya bangunan Pura Batur Pucangan. Pura Batur Pucangan merupakan salah satu bangunan suci sebagai simbol penghormatan untuk beliau disungsung (dipuja) oleh masyarakat Desa Buahan dan masyarakat dari luar Desa Buahan, mengingat rasa baktinya pada beliau sebagai Raja Tabanan.

Puri yang terdapat di Desa Buahan bernama Puri Pucangan. Puri Pucangan yang terletak di Selatan dari Pura Desa (kiduling Bale Agung) mengalami perubahan yang awalnya merupakan istana pada zaman kerajaan. Kemudian setelah zaman kerajaan hingga saat ini terjadi perubahan fungsi menjadi pura yang bernama Pura Agung Sira Arya Kenceng Buahan Pucangan. Adapun perubahan nama dan fungsi juga terjadi pada Taman Puri yang terletak di Tenggara Desa Buahan pada zaman kerajaan, saat ini difungsikan menjadi Pura Taman Sari. Berdasarkan sejarah di Desa Buahan pembagian ruang didasari konsep Tri Mandala, dimana Puri sebagai Utama Mandala, area terbangun atau permukiman sebagai Madya Mandala, dan area tak terbangun yang termasuk kedalamnya yaitu karang bengang merupakan bagian dari Nista Mandala, ini mempengaruhi mengapa letak karang bengang menjadi area terluar dari Desa Buahan, yang menjadi area batas antar desa.

\subsubsection{Demografi}

Lokasi pada tapak berada di Desa Buahan, Kecamatan Tabanan, Kabupaten Tabanan, dengan jumlah penduduk yang relatif padat. Berdasarkan data yang diperoleh dari Monografi Desa Buahan Tahun 2019, jumlah penduduk yang berada di Desa Buahan sebanyak 2.648 jiwa, terdiri atas 1.294 jiwa laki-laki dan 1.354 jiwa perempuan. Pada tahun 2018 kepadatan jumlah penduduk di Desa Buahan sebanyak 409 Jiwa $/ \mathrm{km}^{2}$ dan mengalami peningkatan pada tahun 2019 menjadi 410 Jiwa $/ \mathrm{km}^{2}$. Jika dilihat dari jumlah pemilik usaha tani pada sektor pertanian sebanyak 1.082 orang dan pemilik usaha perkebunan pada sektor perkebunan sebanyak 786 orang.

\subsection{Karang Bengang Ditinjau Dari Aspek Biofisik}

Kondisi biofisik yang terdapat pada karang bengang di Desa Buahan merupakan salah satu elemen yang termasuk dalam pembentuk karakter lanskap budaya, meliputi kondisi iklim (curah hujan), dan elemen lanskap (McClelland et al, 1999). Karang bengang di Desa Buahan terletak di Kabupaten Tabanan yang merupakan daerah beriklim tropis. Menurut data dari Badan Meteorologi Klimatologi dan Geofisika (BMKG) Wilayah III Denpasar (2019), curah hujan bulanan periode 2014-2018, total curah hujan tertinggi terjadi pada tahun 2017 dengan curah hujan $3047,0 \mathrm{~mm}$ dan total curah hujan terendah pada tahun 2015 dengan curah hujan $1519,5 \mathrm{~mm}$. Lahan basah memiliki minimal curah hujan $1500 \mathrm{~mm}$ pertahun. Pada lahan kering berupa tegalan curah hujan minimal kurang dari $1500 \mathrm{~mm}$ pertahun dan hutan yang memiliki curah hujan lebih dari $1500 \mathrm{~mm}$ pertahun dapat digolongkan kedalam hutan hujan tropis (Wahyunto \& Shofiyanti, 2012). Berdasarkan curah hujan ini, mendukung terbentuknya tipologi lahan yang di dominasi lahan persawahan dan tegalan maupun hutan. Curah hujan yang mempengaruhi potensi air yang cukup tinggi untuk keberlangsungan tersedianya kebutuhan air yang mengairi area pada karang bengang di Desa Buahan, Curah hujan yang cukup tinggi pada area karang bengang mempengaruhi keanekaragaman vegetasi pada karang bengang di Desa Buahan. Berdasarkan hasil pengamatan, elemen lunak yang berupa vegetasi terdapat pada karang bengang di Desa Buahan didominasi tanaman padi, bambu, kelapa, pisang dan kakao. Vegetasi yang beragam ditemui pada karang bengang, salah satunya menjadi komoditas utama.

Jenis sektor pertanian dengan komoditas utama yaitu padi (Oryza sativa) dan pada sektor perkebunan dengan komoditas utama kakao (Theobroma cacao) dan kelapa (Cocos nucifera). Keanekaragaman vegetasi lain yang terdapat di karang bengang di Desa Buahan seperti Bambusa sp., Artocarpus altilis, Gliricidia sepium, Erythrina fusca, Carica papaya, Colocasia esculenta, Cadiaeum variegatum, Cordyline terminalis, Musa paradisiaca, Hibiscus rosa-sinensis, Cyperus rotundus L., Imperta cylindrica L., dan Diplazium wichuraedan serta curah hujan yang cukup tinggi dan adanya campur tangan manusia dalam pengelolaan karang bengang pada konsep Tri Hita Karana yang mempengaruhi kehidupan 
manusia sebagai pengguna karang bengang di Desa Buahan (Adhika, 2004). Hasil campur tangan manusia sebagai bagian dari implementasi hubungan manusia dengan alam, manusia dengan manusia, manusia dengan Tuhan yang terlihat dengan adanya elemen keras berupa pancoran, pondokan petani dan Pelinggih Catu.

Didukung curah hujan yang cukup dan topografi Desa Buahan yang landai dengan nilai berkisar 165-227 mdpl. Topografi Desa Buahan tertinggi sekitar 227 mdpl dan terendah 165 mdpl. Khususnya pada area karang bengang di Desa Buahan, terletak pada topografi yang landai dengan kontur rata-rata pada ketinggian $200 \mathrm{mdpl}$ dan dikelilingi 2 sungai yaitu sungai yeh tabah dan sungai yeh pembungan yang dapat memenuhi kebutuhan air untuk area persawahan dan area tegalan maupun hutan pada area karang bengang di Desa Buahan secara merata, karena mengalirnya air mengikuti kontur yang lebih tinggi dibagian Utara karang bengang mengalir kearah Selatan pada area karang bengang di Desa Buahan.

\subsection{Karang Bengang Ditinjau Dari Aspek Sosial}

Menurut McClelland et al. (1999) karakteristik lanskap budaya terbentuk dari sebelas elemen salah satunya aktivitas, pola organisasi ruang, respon terhadap alam, dan tradisi budaya. Kondisi sosial masyarakat yang terdapat pada kawasan karang bengang di Desa Buahan, meliputi: sosial budaya, dan ekonomi. Partisipasi masyarakat melakukan pembangunan dibidang ekonomi yang sebagian besar masyarakat Desa Buahan bermata pencaharian di sektor pertanian. Ini juga karena tipologi lahan yang merupakan lahan persawahan. Perkembangan dan pengelolaan karang bengang di Desa Buahan beriringan tidak terlepas dari kondisi sosial dimasyarakat dan budaya yang diwariskan turun temurun.

Budaya yang merupakan bagian dari kearifan lokal yang beriringan dengan kepercayaan yang dianut oleh masyarakat sebagai pengguna karang bengang itu sendiri, sehingga secara tidak langsung, kearifan lokal tersebut sudah melekat dalam kehidupan sehari-hari bagi masyarakat sebagai pengguna karang bengang. Kearifan lokal pada implementasi konsep Tri Hita Karana pada elemen seperti Pancoran merupakan implementasi dari hubungan manusia dengan alam dalam pengelolaan sumber mata air yang dimanfaatkan untuk kehidupan sehari-hari. Pondokan petani merupakan implementasi dari hubungan manusia dengan manusia dalam berinteraksi antara petani di area karang bengang di Desa Buahan. Pelinggih Catu merupakan implementasi hubungan manusia dengan Tuhan dalam kegiatan pertanian sebagai rasa syukur para petani dengan Tuhan pada area karang bengang di Desa Buahan. Kegiatan sehari-hari dalam kehidupan masyarakat pada area karang bengang di Desa Buahan dengan kondisi fisik berupa kawasan yang sebagian besar dan dimanfaatkan untuk area persawahan, karang bengang di Desa Buahan merupakan bagian dari Subak Empas Buahan dengan pekasehnya yang bernama I Wayan Tantra. Adapun sumber air yang mengairi lahan persawahan di karang bengang di Desa Buahan ini yaitu air dari aliran sungai yeh tabah dan yeh pembungan. Sumber mata air yang menjadi implementasi konsep Tri Hita Karana yaitu pancoran tingkih dan pancoran taman yang biasa dimanfaatkan untuk mencuci dan mandi oleh masyarakat Desa Buahan, terlihat pada Gambar 3.
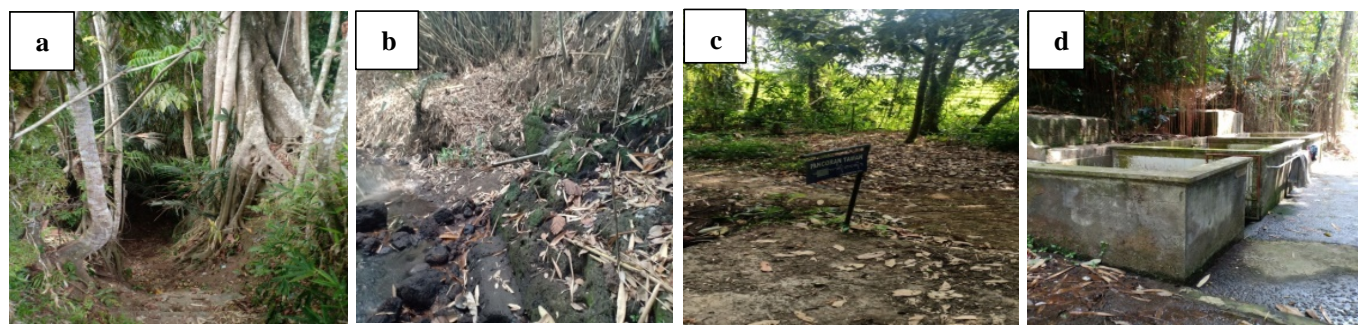

Gambar 3. Berbagai Kondisi Pancoran di Desa Buahan (a) Jalan Masuk Pancoran Tingkih, (b) Pacoran Tingkih, (c) Jalan Masuk Pancoran Taman, dan (d) Pancoran Taman

Hasil wawancara dengan bendesa adat Desa Buahan Bapak I Wayan Muliada pada karang bengang di Desa Buahan, pada hari-hari tertentu dilaksanakan kegiatan Yadnya (upacara). Salah satunya bertepatan pada Tilem Keenam (pada bulan keenam, bulan mati menurut tahun caka) setiap tahunnya dilaksanakan Upacara nangluk mrana. Menurut Widyantari, dkk (2018) nangluk mrana berasal dari kata bahasa Bali yang mendapat pengaruh bahasa sansekerta. nangluk atau tangluk berarti tanggul, pagar, 
penghalang, atau pembatas dan mrana berarti hama atau wabah penyakit dan mrana adalah istilah yang umum dipakai untuk menyebut jenis-jenis penyakit yang merusak tanaman. Bentuknya bisa berupa serangga, binatang maupun dalam bentuk gangguan keseimbangan alam yang berdampak merusak tanaman yang mempengaruhi hasil pertanian masyarakat. Nangluk merana dapat didefinisikan sebagai kegiatan upacara untuk mencegah atau menghalangi wabah penyakit maupun hama, atau bisa dikatakan juga ritual penolak bala yang dilakukan pada area terluar dari permukiman sebagai tangluk (pembatas atau tembok).

Tangluk pada Desa Buahan yaitu area karang bengang dan dua sungai yang mengapit yang masih ada sampai sekarang yaitu sungai yeh pembungan dan sungai yeh tabah sebagai bagian terluar Desa Buahan di bagian Selatan yang terdahulunya sebagai batas desa sebelum adanya sistem administrasi desa. Adanya upacara nangluk mrana pada area tangluk atau batas terluar di Desa Buahan tepatnya karang bengang merupakan area pelestarian budaya, dimana karang bengang di Desa Buahan sangat penting keberadaannya selain merupakan tempat berlangsungnya upacara nangluk mrana, adapun fungsi lain dari upacara nangluk mrana sebagai realisasi dari konsep Tri Hita Karana yaitu dilihat dari fungsi religius sebagai permohonan dan rasa syukur terhadap Tuhan dengan manifestasiNya sebagai Ida Bhatara Sri yang telah memberikan kesejahteraan bagi petani, dari fungsi sosial adanya interaksi antar pemilik lahan pada area karang bengang di Desa Buahan dan interaksi serta gotong royong antar masyarakat Desa Buahan dalam melaksanakan upacara sebagai mahluk sosial, dan dilihan dari fungsi konservasi lahan yang mampung bertahan hingga saat ini berdasarkan kesadaran masyarakat akan pentingnya pengelolaan sumber daya alam baik berupa vegetasi maupun sumber mata air dalam keberlangsungan memenuhi kebutuhan seharihari masyarakat di Desa Buahan. Selain upacara nangluk mrana ada juga upacara lain yaitu ngusaba nini, ngusaba desa dan caru desa yang juga dilaksanakan pada waktu-waktu tertentu. Contoh upacara nangluk mrana terlihat pada Gambar 4.

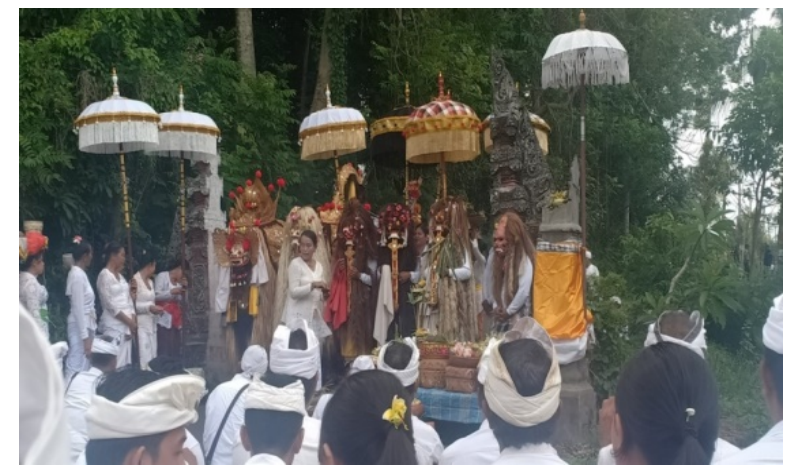

Gambar 4. Upacara Nangluk Mrana

\subsection{Indentifikasi Karang Bengang Ditinjau dari Pola Ruang Kecamatan, Pola Ruang Desa Buahan, Dan Pola Sebaran Karang Bengang}

Berdasarkan peta tutupan lahan Kecamatan Tabanan, didapatkan pola permukiman yang dominan terpusat di tengah dari Kecamatan Tabanan pada Desa Dauh Peken, Delod Peken, dan Desa Dajan Peken dan dikelilingi sebaran yang didominasi area persawahan dan area hijau yang berupa hutan dan tegalan yang bisa dikatakan minim permukiman atau permukimannya yang tersebar dibeberapa bagian dan tidak terpusat di satu kawasan, seperti yang terjadi pada pola permukiman terpusat berdasarkan teori bentukbentuk pola permukiman penduduk (Wiraprama dkk, 2014). Karang bengang di Desa Buahan terletak pada bagian area yang didominasi area persawahan dan area hijau. Pada pola-pola yang terbentuk pada skala kecamatan menggambarkan bagaimana pembagian ruang yang memusat, homogen pada distrik (Lynch, 1960). Pola ruang dari Kecamatan Tabanan merujuk pada Gambar 5. 


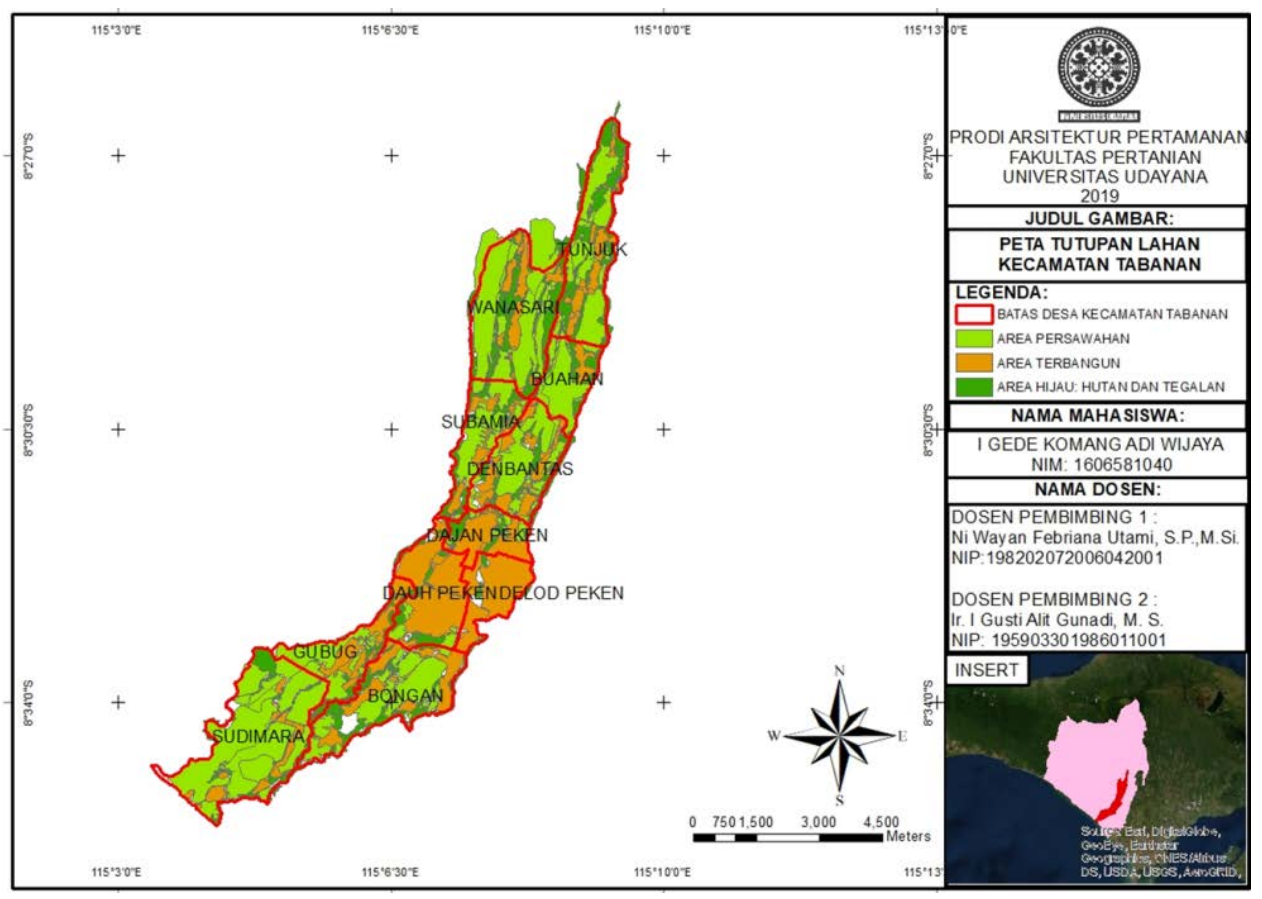

Gambar 5. Tutupan Lahan Kecamatan Tabanan

(Sumber: Google Earth, 2019 dengan Pengolahan Data Menggunakan ArcMap 10.4.1)

Bila dilihat dari skala kecamatan, kategori pengelompokan ruang bisa dibagi menjadi area terbangun yaitu area permukiman yang homogen dan area tak terbangun yaitu area persawahan, area hutan, maupun area tegalan. Pengelompokan area-area ini membentuk sebuah pola (Forman \& Gordon, 1986). Berdasarkan peta tutupan lahan Kecamatan Tabanan, pola yang terbentuk dapat disederhanakan menjadi 2 bagian lahan yang didominasi area tak terbangun tersebar diluar area terbangun, dan area terbangun didominasi terpusat di tengah-tengah Kecamatan Tabanan.

Pada Gambar 5 terlihat bahwa area permukiman yang mendominasi berada di tengah dan berada diantara area tak terbangun. Pola Kecamatan Tabanan ini juga mempengaruhi pola ruang pada skala desa. Pola seperti ini menjadi dasar terbentuknya area karang bengang yang merupakan implementasi dari area yang didominasi area tak terbangun atau area hijau. Pada skala desa juga terdapat pola yang serupa dan terdapat pola yang terbagi menjadi kelompok area terbangun dan area tak terbangun khususnya pada Desa Buahan.

Pada peta tutupan lahan di Desa Buahan tergambarkan juga pola yang serupa dengan pola yang ada pada pola skala kecamatan namun terlihat lebih jelas. Pada skala desa, dapat juga dikelompokan menjadi area terbangun dan area tak terbangun yang terpusat pada titik- titik tertentu. Pola ini didasari dari adanya konsep Tri Mandala yaitu utama mandala, madya mandala, dan nista mandala (Raharja, 2016) dimana yang menjadi utama mandala di Desa Buahan adalah Puri sebagai pusat pemerintahan atau sekarang dikenal dengan Pura Agung Sira Arya Kenceng Pucangan Buahan, madya mandala yaitu permukiman yang homogen yang memusat mengelilingi Puri, dan nista mandala yaitu area karang bengang Desa Buahan, merujuk pada Gambar 6. 


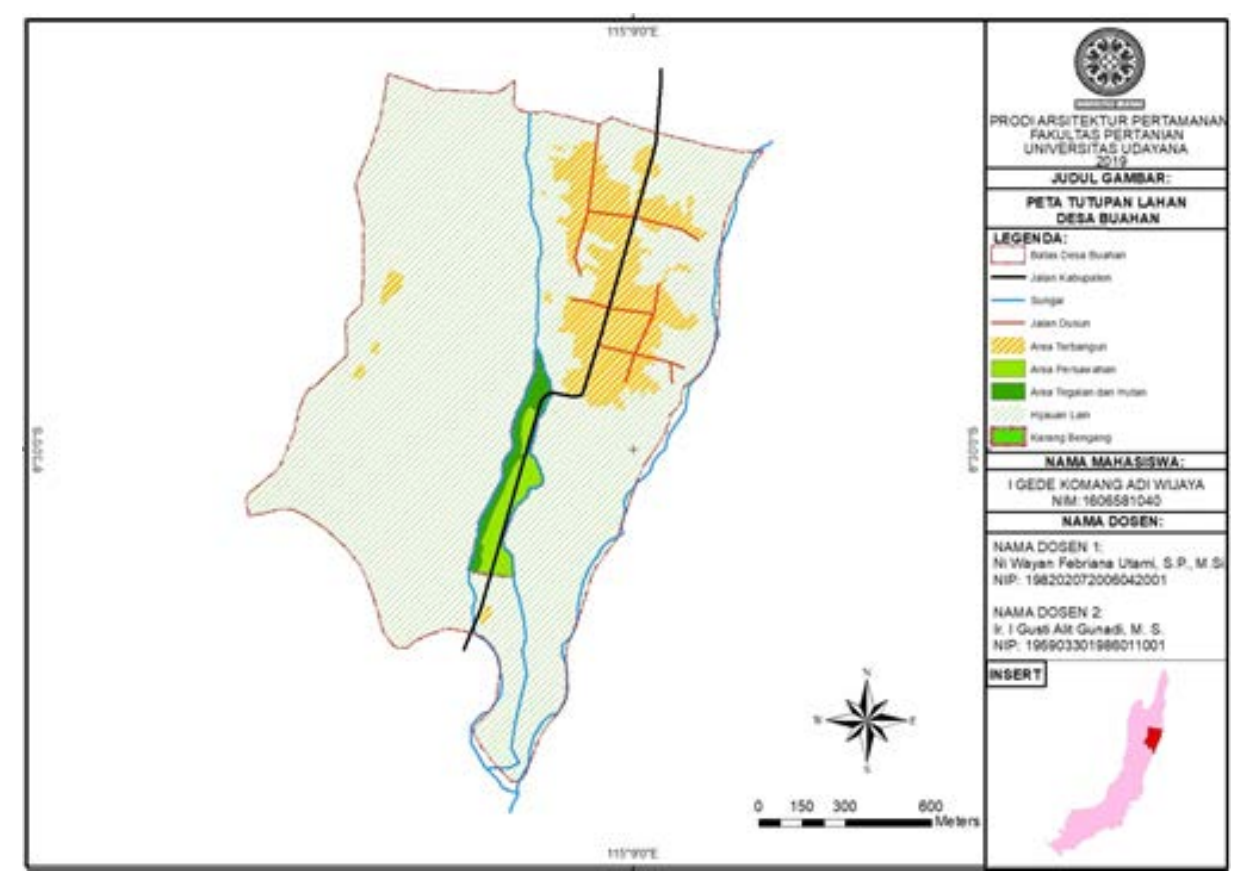

Gambar 6. Tutupan Lahan Desa Buahan

(Sumber: Google Earth, 2019 dengan Pengolahan Data Menggunakan ArcMap 10.4.1)

Pola yang terdapat pada Gambar 6 menunjukkan bahwa pola area terbangun memusat dan mengelompok. Namun terdapat juga pola linear terlihat pada Desa Buahan. Pada area karang bengang didalamnya dibagi menjadi area persawahan dan area hijau seperti tegalan dan hutan yang mengikuti sungai, biasanya terdapat pada desa dataran rendah yang dikatakan bentuk desa linear (Daldjoeni, 2018).

Area terbangun yang merupakan bagian dari madya mandala di Desa Buahan tersusun secara turun temurun dari area permukiman yang merupakan lingkungan tempat tinggal penduduk Desa Buahan. Area terbangun di Desa Buahan memiliki bentuk desa terpusat dan mengelompok yang berada di antara area tak terbangun, seperti yang terjadi di kawasan pegunungan berdasarkan teori bentuk dan pola desa (Daldjoeni, 2018). Salah satu bentuk permukiman di Desa Buahan di bagian Selatan, tengah dan bagian Utara Desa Buahan. Ini menggambarkan bagaimana permukiman yang mengelompok dan memusat saling berdampingan antar tiap rumah di Desa Buahan.terlihat pada Gambar 7.
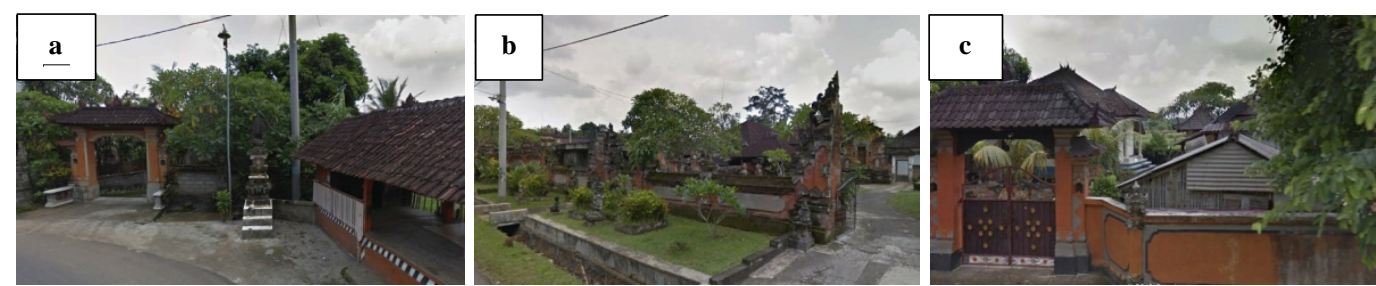

Gambar 7. Karakteristik Permukiman di Desa Buahan Bagian Selatan (a), Tengah (b), dan Utara (c)

Area tak terbangun merupakan area minim aktivitas manusia. Area tak terbangun di Desa Buahan berupa area persawahan, tegalan dan hutan yang dikelola oleh masyarakat setempat, dan bagian dari area Desa Adat Buahan. Salah satunya yang termasuk kedalam area tak terbangun yaitu area karang bengang di Desa Buahan. Karang bengang di Desa Buahan dikelola oleh Subak, yaitu Subak Empas dengan pekasehnya Bapak I Wayan Tantra serta dikelola juga oleh masyarakat Desa Buahan itu sendiri.

Pada area karang bengang di Desa Buahan dibagi menjadi area persawahan, tegalan,dan hutan yang berada diantara dua sungai yaitu sungai yeh tabah disebelah Barat, dan sungai yeh pembungan disebelah Utara sampai di Timur karang bengang Desa Buahan. Karang bengang merupakan implementasi ruang terbuka hijau skala desa, sebagai penerapan konsep tradisional Bali yaitu Tri Hita Karana dan Tri 
Mandala. Area karang bengang di Desa Buahan juga dilindungi regulasi pada tingkat desa berupa perarem (kesepakatan desa). Hasil wawancara Bendesa Adat Buahan Bapak I Wayan Muliada menyatakan bahwa setiap pembangunan yang dilakukan pada area karang bengang di Desa Buahan oleh pemiliki lahan dari luar Desa Buahan dikenakan biaya 40 juta rupiah yang dibayarkan ke Desa Adat Buahan, ini bertujuan sebagai upaya konservasi lahan dari alih fungsi lahan.

Hasil observasi pada tapak menunjukan bahwa karakteristik vegetasi yang mendominasi pada area karang bengang adalah tanaman padi pada area sawah, tanaman pisang, kelapa, dan kakao pada area tegalan, tanaman bambu pada area hutan. Karang bengang di Desa Buahan merupakan area yang memiliki proporsi lahan tertentu yang tersusun dari area persawahan, area tegalan maupun hutan. Pada karang bengang di Desa Buahan juga terdapat elemen keras (hardscape) yaitu pancoran, sebagai pemanfaatan sumber mata air. Karang bengang di Desa Buahan memiliki dua pancoran yaitu pancoran taman dan pancoran tingkih. Sebaran karang bengang di Desa Buahan terlihat pada Gambar 8.

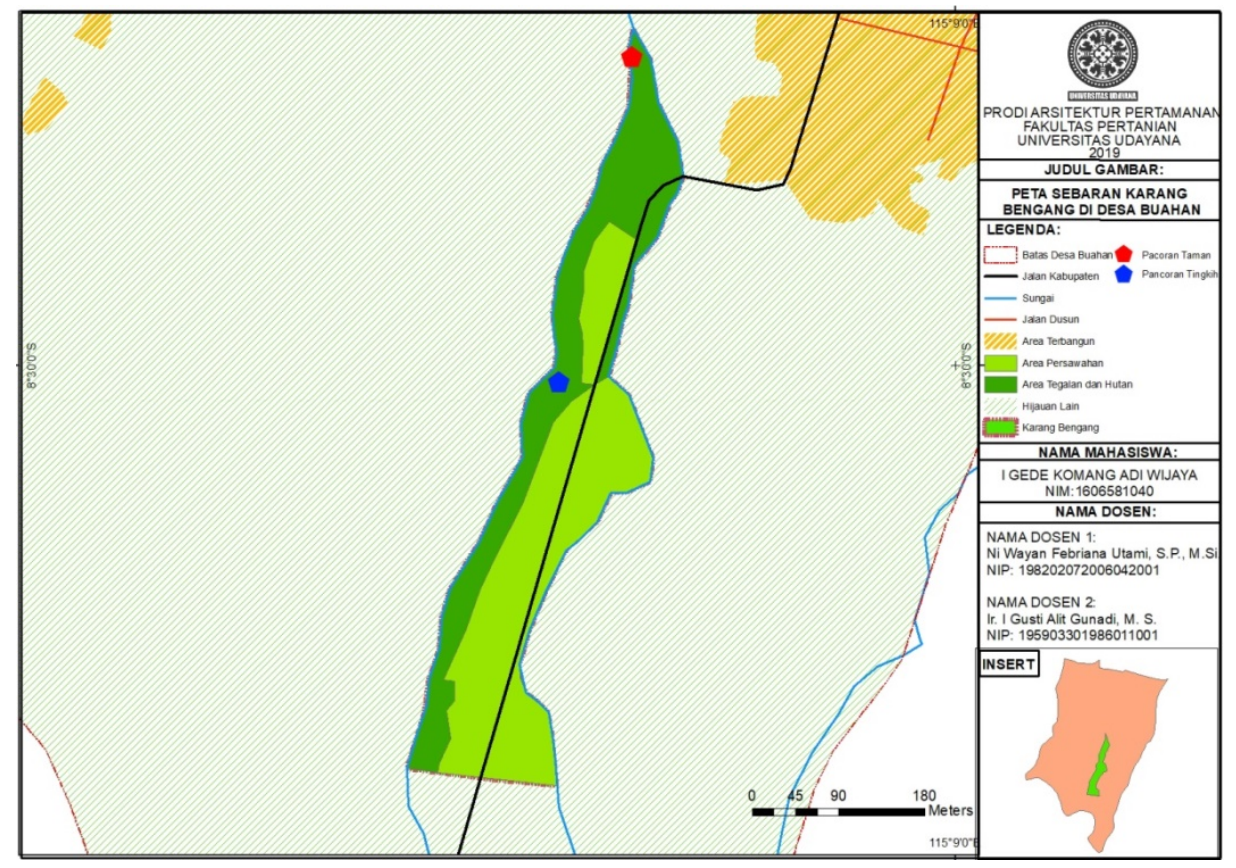

Gambar 8. Peta Sebaran Karang Bengang di Desa Buahan

(Sumber: Google Earth, 2019 dengan Pengolahan Data Menggunakan ArcMap 10.4.1)

Luas Desa Buahan yaitu 6,4586 km², dengan luas area karang bengang mencapai $70.176 \mathrm{~m}^{2}$. Karang bengang di Desa Buahan seperti yang dillustrasikan pada peta berdasarkan analisi spasial dengan disimbolkan warna hijau muda yang melambangkan area persawahan dan warna hijau tua melambangkan tegalan dan hutan pada area karang bengang. Jika dihitung luas area menggambarkan dominasi lahan persawahan dengan luas yaitu $40.928 \mathrm{~m}^{2}$ dan luas area tegalan dan hutan yaitu $29.248 \mathrm{~m}^{2}$. Berdasarkan persentase area persawahan mencapai $58,3 \%$ dari total luasan area karang bengang di Desa Buahan, dan area tegalan dan hutan persentasenya mencapai $41,7 \%$.

\section{Simpulan}

Karang bengang di Desa Buahan memiliki pola ruang yang mengikuti kaidah pola ruang tradisional Bali yaitu, Tri Mandala dan Tri Hita Karana (seperti adanya hubungan manusia dengan manusia yang diimplementasikan dengan adanya pondokan petani sebagai tempat interaksi antar petani, manusia dengan alam dimplementasikan pada area persawahan, tegalan, hutan, serta pancoran dengan bentuk aktivitasnya pemanfaatan sumber daya alam, dan hubungan manusia dengan Tuhan yang diimplementasikan pada area suci yaitu Pelinggih Catu). Karang bengang di Desa Buahan memiliki karakter lanskap budaya berdasarkan beberapa elemen (pola organisasi ruang pembagian antara area persawahan, hutan dan tegalan, tradisi 
nangluk mrana, respon terhadap alam berupa implementasi dari konsep Tri Hita Karana). Karakter lanskap yang ditemukan tersebut mencakup instrumen pembentuk lanskap budaya yang bersifat tidak nyata (intangible). Ditemukan juga elemen-elemen yang termasuk komponen fisik pembentuk lanskap, yaitu jalan aspal, tanaman produksi, pancoran tingkih dan pancoran taman, pelinggih catu, pondokan petani, area karang bengang yang memiliki fungsi khusus sebagai tempat upacara pada waktu-waktu tertentu, dan situs arkeologi berupa karang bengang beserta elemen skala kecil yaitu pancoran tingkih, pancoran taman, dan pelinggih catu.

\subsection{Saran}

Karang bengang merupakan produk dari konsep tradisional Bali berlandaskan konsep Tri Hita Karana dan Tri Mandala, yang dipengaruhi perkembangan masyarakat. Pada perkembangannya, perlu adanya batasan berupa penguatan regulasi pada tingkat desa yaitu perarem (kesepakatan desa) dan awigawig (aturan desa), yang dilakukan untuk menekan terjadinya alih fungsi lahan pada karang bengang. Penataan yang lebih terstruktur dan tidak menghilangkan konsep ruang tradisional Bali sebagai bagian dari warisan leluhur perlu dikembangkan kedepannya dalam upaya dalam menjaga kelestarian lanskap karang bengang di Desa Buahan.

\section{Daftar Pustaka}

Adhika, I. M. 2004. Pola Penataan Ruang Unit Pekarangan Di Desa Bongli Tabanan. Permukiman Natah, 2(1):1-9.

BMKG. 2019. Badan Meteorologi Klimatologi dan Geofisika (BMKG) Wilayah III Denpasar (2019) dari Pos Hujan Marga.

BPS. 2018. Kecamatan Tabanan Dalam Angka (I. G. G. N. Sudarmayasa \& N. Darmawan, Eds.). Tabanan.

Buahan, M. D. 2019. Daftar Isian Tingkat Perkembangan Desa Dan Kelurahan., Available online at: prodeskel.binapemdes.kemendagri.go.id/mdesa/\# (diakses pada 27 November 2019).

Daldjoeni, N. 2018. Geografi Kota dan Desa. Editors: Nugrahini, K., N. Yogyakarta: Penerbit Ombak.

Forman, R. T. T., M. Gordon. 1986. Landscape Ecology. New York: John Willey and Sons.

Raharja, M. 2016. 110 Tahun Puputan Badung: Merangkai Dokumen Arsitektur Puri Denpasar. 1-9.

Karma, M. P. 2018. Perkembangan Pemanfaatan Area Karang Bengang Di Antara Desa Pakraman Tegallalang Dan Sapat. UNDAGI: Jurnal IImiah Arsitektur 6(1):1-12.

Lynch, K. 1960. The Image of the City. The Journal of Aesthetics and Art Criticism 21(1):91.

McClelland, L. F., J. T. Keller, G. P.Keller, and R. Z. Melnick. 1999. National Register Bulletin 30: Guidelines for evaluating and documenting rural historic landscapes. Washington, DC: US National Park Service.

Republik Indonesia. Peraturan Presiden Republik Indonesia Nomor 51 Tahun 2014. Tentang Rencana Tata Ruang Kawasan Perkotaan Denpasar, Badung, Gianyar, Dan Tabanan.

Sugiyono. 2004. Metode Penelitian Kombinasi. Bandung: CV Alfabeta.

Sugiyono. 2010. Metode Penelitian Kuantitatif, Kualitatif dan R\&D. Bandung: Alfabeta.

Wahyunto, R. Shofiyant. 2012. Wilayah Potensial Kekeringan Untuk Mendukung Pemenuhan Kebutuhan Pangan Di Indonesia. Ketahanan Pangan, p. 315.

Widyantari, N. M. N., N. W. Sumertini, I. M. Wika. 2018. Upacara Nangluk Merana di Desa Adat Kuta Kecamatan Kuta Kabupaten Badung (Kajian Filosofi). Journal of Chemical Information and Modeling, 53(9):1689-1699.

Wiraprama, A. R., Zakaria, A. W. Purwantiasning. 2014. Kajian Pola Permukiman Dusun Ngibikan Yogyakarta dikaitkan dengan Perilaku Masyarakatnya. Jurnal Arsitektur NALARs. 